\title{
Study on Decision Method of Neutral Point Grounding Mode for Medium-Voltage Distribution Network
}

\author{
Hengyong Liu1, Xiaofu Xiong², Jinxin Ouyang², Xiufen Gong², Yinghua Xie', Jing Li1 \\ ${ }^{1}$ Shenzhen Power Supply Co. Ltd., Shenzhen, China \\ ${ }^{2}$ State Key Laboratory of Power Transmission Equipments \& System Security and New Technology, \\ College of Electrical Engineering, Chongqing University, Chongqing, China \\ Email: gxfcqu@qq.com
}

Received February 2014

\begin{abstract}
The neutral grounding mode of medium-voltage distribution network decides the reliability, overvoltage, relay protection and electrical safety. Therefore, a comprehensive consideration of the reliability, safety and economy is particularly important for the decision of neutral grounding mode. This paper proposes a new decision method of neutral point grounding mode for mediumvoltage distribution network. The objective function is constructed for the decision according the life cycle cost. The reliability of the neutral point grounding mode is taken into account through treating the outage cost as an operating cost. The safety condition of the neutral point grounding mode is preserved as the constraint condition of decision models, so the decision method can generate the most economical and reliable scheme of neutral point grounding mode within a safe limit. The example is used to verify the feasibility and effectiveness of the decision method.
\end{abstract}

\section{Keywords}

Distribution Network; Neutral Grounding Mode; Reliability; Decision Method; Objective Function

\section{Introduction}

The neutral grounding mode of medium-voltage distribution network is closely related to the reliability, overvoltage and insulation coordination, relay protection, communication signal system interference, electrical safety and grounding devices[1] [2]. When a fault occurs, the single-phase grounding current of neutral point ungrounded system only determined by the system capacitance to earth, the fault can be automatically eliminated in most cases, but the intermittent arc grounding over voltage is large, high insulation level is demanded. In the arc suppression coil grounding system, the single-phase ground fault current only rarely compensated as residual current, has obvious inhibiting effect for the arc reignition which can reduce the probability of high amplitude arc grounding overvoltage, but the regulation of resonance degree is hard and the fault line selection has not yet been achieved 100\% accuracy, which will seriously affect the normal power supply restoration [3]. The small resistance grounding mode can effectively restrain the resonance over voltage and arc grounding overvoltage, 
the power frequency overvoltage is low, the insulation level of transmission line and equipment requirements and the total costs are lower than the arc suppression coil grounding mode, the single-phase grounding fault detection has high sensitivity, but also because of the large grounding fault current, the potential rise higher, adverse to the personal and equipment safety, and the protection clear the fault rapidly, cause the power supply intermittent [4].

To choose a reasonable, safe and efficient neutral grounding mode of the power grid can guarantee the reliability and safety of the power network and also can avoid causing large economic investment, which has great significance for the efficient operation of power system. Large amounts of references have researched on the influence of different neutral grounding mode. References [5]-[7] according to the capacitive current magnitude of Suzhou, Wuhan and Guizhou area, put forward the neutral point grounding mode suitable for them respectively. References [8]-[10] focus on the analysis of neutral grounding via low resistance and grounding by arc suppression coil the advantages and disadvantages of the two methods, and points out that the small resistance grounding mode in power supply reliability depends on the network structure and the automation level, but the arc suppression coil grounding mode will have technical and economic advantages through the optimization of automatic tuning device.

Nowadays, a common simple method to realize the selection of the neutral grounding mode of medium- voltage distribution network mainly through the influence comparison between them, there is still lack of quantitative neutral point grounding mode decision method. The reference [11] using experts scoring method to arrive the neutral point grounding mode choice factors, weight the relative value of the factors in different neutral grounding modes, choose the grounding mode which has the maximum weighted total value. The reference [12] according to the influence factors of neutral point grounding mode, establishes the corresponding membership function, through fuzzy theory to build the neutral point grounding mode decision method. The reference [13] [14] by comparing the fault tripping rate relative superiority degree of different neutral point grounding mode, to evaluate the neutral grounding mode.

The lack of neutral point grounding mode decision method leads to great impact on power system planning and operation. This paper presents a comprehensive neutral grounding modes for distribution network, which integrates the influence of reliability, safety and economy, combine the reliability evaluation of distribution network under various neutral grounding modes and the economic operation cost which included in the safety factors together, calculate life cycle cost of the distribution network under various neutral grounding modes and combining the reliability index as constraint conditions to achieve the neutral grounding mode decision.

\section{Neutral Point Grounding Mode Decision Method}

The decision method makes use of the optimization idea [15] [16], lets economic index optimal as objective function, the reliability index as constraint conditions to establish the neutral point grounding mode decision model. As the objective function:

$$
\min W=G+X+K+F
$$

Constraint conditions:

$$
\left\{\begin{array}{l}
A S A I \geq A_{\Gamma} \\
C A I D I \leq C_{\Gamma} \\
\left|P_{j}\right| \leq P_{j \max } \\
U_{j \min } \leq U_{j} \leq U_{j \max } \\
I_{i j} \leq I_{i j \max } \\
P_{j}=q_{j}+\sum_{k=1}^{L_{j}} P_{j k}
\end{array}\right.
$$

In the formula, $W$ stands for the whole life cycle cost of the neutral point grounding mode, $G$ stands for equipment input cost which consider the safety factors, $X$ stands for maintenance cost, $K$ stands for the outage cost, $F$ stands for obsolete cost, these costs are uniform annual value [17]; ASAI stands for the system average service availability index of each neutral point grounding mode, CAIDI stands for the customer average interruption duration index of each neutral point grounding mode, $A_{\Gamma}$ stands for the average service 
availability index value for an actual network required, $C_{\Gamma}$ stands for the customer average interruption duration index value for an actual network required; $P_{j}$ and $P_{j \max }$ respectively to the transmission power and the maximum allowable power for the load point $\mathrm{j} ; U_{j \min }$ and $U_{j \max }$ stands for the maximum and minimum limit voltage value for the load point $\mathrm{j} ; q_{j}$ stands for the load value of the load point $\mathrm{j} ; L_{j}$ stands for the total load point number; $P_{j k}$ stands for the section line k's power which supplied by the load point j; $I_{i j}$ and $I_{i j \max }$ stands for the line current and the maximum allowable current.

The decision method considers the influence about the reliability of distribution network with different neutral grounding mode, using the reliability parameter to evaluate the distribution network reliability for different neutral grounding mode. Transfer the expected energy not supplied index to the outage cost, as an objective function which takes the other reliability factors into account, makes the average supply availability index and customer average interruption duration index as the reliability constraints. The process is shown in Figure $\mathbf{1}$.

\section{Neutral Point Grounding Mode Decision Objective Function}

\subsection{Equipment Input Cost $G$}

The equipment input cost which considering the safety factors includes the cost of the initial investment in equipment and operating added facilities investment:

$$
G=\sum_{i=1}^{m}\left[\frac{k(1+k)^{n_{i}}}{(1+k)^{n}-1} p_{i}+a_{i}\right]
$$

In the formula, $m$ stands for the total number of investment items; $n_{i}$ stands for the useful life of investment; $k$ stands for the annual interest rate; $p_{i}$ stands for the initial investment cost of investment; $a_{i}$ stands for the required operating cost for each investment.

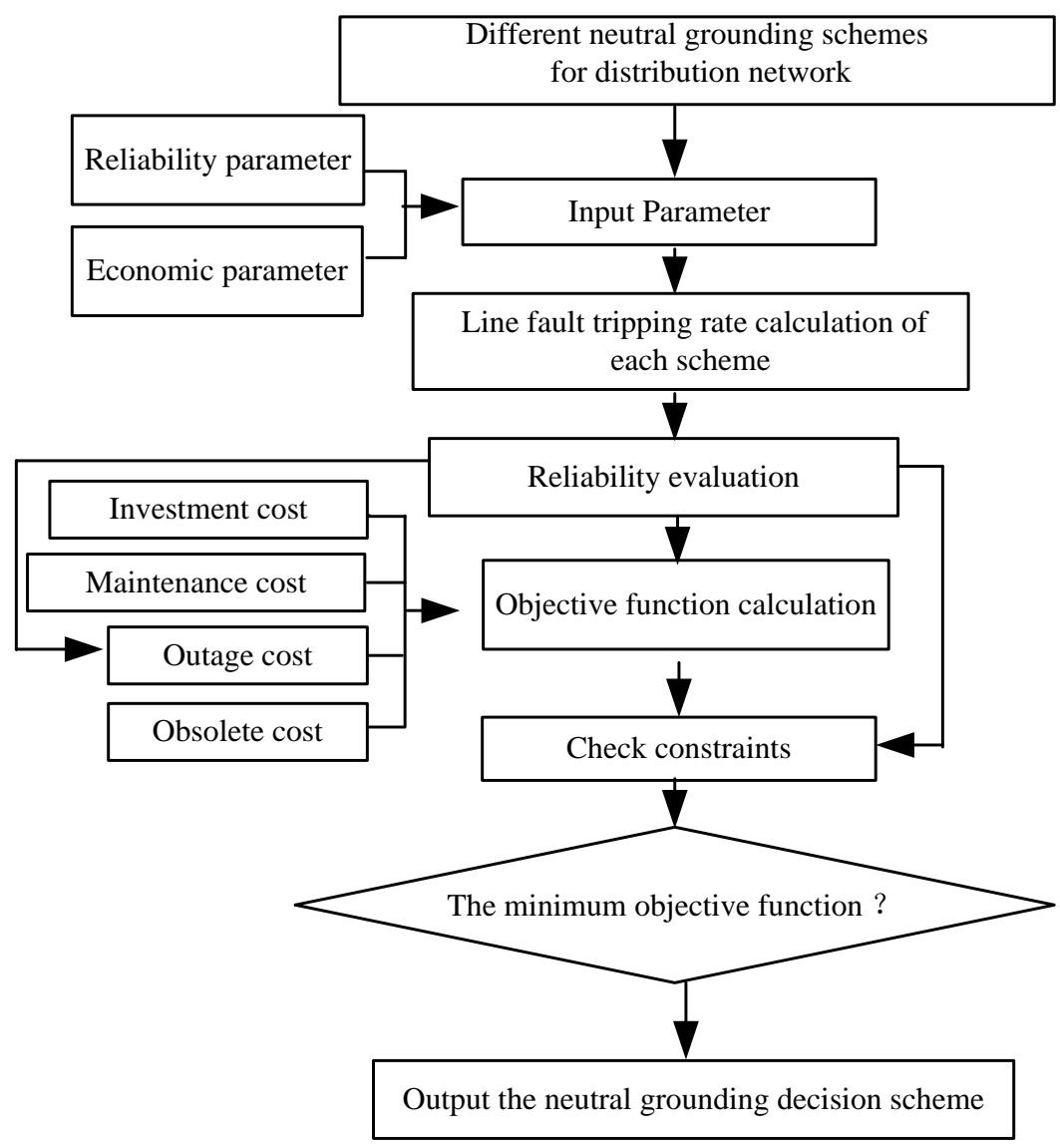

Figure 1. Neutral grounding mode decision process. 
According to the different neutral point grounding scheme, the initial investment which considering the safety factors mainly include the purchase cost of neutral point grounding device, relay protection device, insulation equipment, automation equipment and line selection device, also contain the support of the engineering expenses and other expenses. Among them, the relay protection device, insulation equipment and automation equipment investment are all closely related with the safety factors, such as the use of expensive insulated cable can reduce the risk of electric shock.

The operation investment which considering the safety factors mainly refers to the additional safety protection facilities investment. Including the installation of security fence, cable channel and sidewalk distance in the planning and construction investment to guarantee personal safety.

\subsection{Maintenance Cost $X$}

Maintenance cost includes fault repair cost incurred, and regular inspection cost:

$$
X=\sum_{i=1}^{n} J_{i}
$$

In the formula, $n$ stands for general items of the annual maintenance task; $J_{i}$ stands for the maintenance cost for task $i$, including the cost of materials and labour cost.

\subsection{Outage Cost $K$}

According to the expected energy not supplied index, consider the electricity production ratio and the reliability penalty coefficient [18], can calculate the outage cost:

$$
K=\alpha \times E N S \times c
$$

In the formula, ENS stands for expected energy not supplied of each neutral point grounding mode, which can be obtained from reliability evaluation of different neutral point grounding mode; $\alpha$ stands for the reliability penalty coefficient of anunal outage loss, usually value for $1-2$; c stands for the area's electricity production ratio, refers to the output value creation of the region within a year(expressed in monetary form) and the consumption of electricity ratio:

$$
c=G D P_{i} / E C_{i}
$$

In the formula, $G D P_{i}$ stands for the gross domestic product in price of the region; $E C_{i}$ stands for the total electricity consumption a year of the region.

\subsection{Obsolete Cost $F$}

$$
F=\sum_{i=1}^{p}\left[\frac{k(1+k)^{n_{i}}}{(1+k)^{n}-1} Q_{i}\right]
$$

Where $p$ stands for the total number of equipments; $Q_{i}$ stands for the obsolete cost of equipment $i ; n_{i}$ stands for the service life of equipment $i ; k$ stands for the annual interest rate.

\section{Reliability Index}

Under single-phase grounding fault, the impacts tabulated as the following Table 1, on trip-out rate, outage time and fault propagation vary according to the neutral grounding mode [19].

In the following analysis, $\lambda$ is failure rate of transmission line $i$, the rate of single-phase grounding fault is $\eta$, transient fault is $\delta$, the possibility of overvoltage accident extension is $e_{1}$, the possibility of fire accident is $e_{2}$, the success rate of transient arc extinguish is $\sigma$, under resonance grounding condition the success rate of transient arc extinguishing is $\alpha$, under low resistance grounding condition the failure rate of relay protector sending out trip signal is $\beta$, under low resistance grounding condition the success rate of reclose is $\theta$, under high resistance grounding condition the success rate of protector sending out trip signal is $\varsigma$, the accurate rate of microcomputer based line selection is $\omega$. The models of line fault tripping rate based on different neutral modes are established as follow. 
Table 1. Effects of different neutral grounding mode for distribution network reliability.

\begin{tabular}{|c|c|c|c|}
\hline $\begin{array}{l}\text { eutral grounding } \\
\text { mode }\end{array}$ & Trip-out rate & Outrage Time & $\begin{array}{l}\text { Fault propagation } \\
\text { possibility }\end{array}$ \\
\hline Ungrounded & $\begin{array}{l}\text { Operating with fault for a period } \\
\text { of time under Single-phase fault, } \\
\text { which will be cleared at last. }\end{array}$ & $\begin{array}{l}\text { According to the number } \\
\text { of times of pull tests and } \\
\text { the harmful levels of fault } \\
\text { propagation }\end{array}$ & $\begin{array}{l}\text { Fire caused by arc or } \\
\text { overvoltage accident } \\
\text { expanding are possible }\end{array}$ \\
\hline $\begin{array}{l}\text { Arc suppression } \\
\text { coil grounding }\end{array}$ & $\begin{array}{l}\text { The arc can extinguishes by itself under } \\
\text { single-phase fault, clearing permanent fault } \\
\text { needs the help of line selection devices. }\end{array}$ & $\begin{array}{l}\text { According to the number } \\
\text { of times of pull tests and } \\
\text { the harmful levels of } \\
\text { fault propagation }\end{array}$ & $\begin{array}{l}\text { Fire caused by arc or } \\
\text { overvoltage accident } \\
\text { expanding are possible }\end{array}$ \\
\hline $\begin{array}{l}\text { Low resistance } \\
\text { grounding }\end{array}$ & $\begin{array}{l}\text { Protector response time is based } \\
\text { on the neutral resistance. }\end{array}$ & $\begin{array}{c}\text { According to grid } \\
\text { structure and automaticity }\end{array}$ & Fault expand is less likely \\
\hline $\begin{array}{l}\text { High resistance } \\
\text { grounding }\end{array}$ & $\begin{array}{l}\text { Whether the arc can extinguish by itself under } \\
\text { single-phase fault is based on the neutral } \\
\text { resistance, clearing permanent fault needs the } \\
\text { help of line selection devices. }\end{array}$ & $\begin{array}{l}\text { According to the number } \\
\text { of times of pull tests and } \\
\text { the harmful levels of } \\
\text { fault propagation }\end{array}$ & $\begin{array}{l}\text { Fire caused by arc or } \\
\text { overvoltage accident } \\
\text { expanding are possible }\end{array}$ \\
\hline
\end{tabular}

\subsection{Tripping Rate in Ungrounded Network}

When line $i$ failure, the tripping rate is

$$
P_{i i}=\lambda \eta(1-\delta)+\lambda(1-\eta)=\lambda(1-\eta \delta)
$$

The rate of line $i$ failure but the fault extend to cause the normal line $j$ tripping is

$$
P_{i j}=\lambda \eta(1-\delta)\left(e_{1}+e_{2}-e_{1} e_{2}\right)
$$

\subsection{Tripping Rate in Arc Suppression Coil Grounding Network}

After line $i$ failure, the tripping rate is

$$
P_{i i}=\lambda \eta \delta(1-\alpha)+\lambda \eta(1-\delta)+\lambda(1-\eta)=\lambda(1-\eta \delta \alpha)
$$

The rate of line $i$ failure but the fault extend to cause the normal line $j$ tripping is

$$
P_{i j}=[\lambda \eta \delta(1-\alpha)+\lambda \eta(1-\delta)]\left(e_{1}+e_{2}-e_{1} e_{2}\right)
$$

\subsection{Tripping Rate of Low Resistance Grounding Network}

After line $i$ failure, the tripping rate is

$$
P_{i i}=\lambda \eta \delta(1-\beta)(1-\theta)+\lambda \eta(1-\delta)(1-\beta)+\lambda(1-\eta)=\lambda(1-\eta \beta-\eta \delta \theta+\eta \beta \delta \theta)
$$

The rate of line $i$ failure but the fault extend to cause the normal line $j$ tripping is

$$
P_{i j}=\lambda \eta \delta \beta+\lambda \eta(1-\delta) \beta=\lambda \eta \beta
$$

\subsection{Tripping Rate of High Resistance Grounding Network}

After line $i$ failure, the tripping rate is

$$
P_{i i}=\lambda \eta \delta(1-\sigma)(1-\varsigma)+\lambda \eta(1-\delta)(1-\varsigma)+\lambda(1-\eta)=\lambda \eta \delta \sigma(1-\varsigma)+\lambda(1-\varsigma \eta)
$$

The rate of line $i$ failure but the fault extend to cause the normal line $j$ tripping is

$$
P_{i j}=[\lambda \eta \delta(1-\sigma)+\lambda \eta(1-\delta)] \varsigma\left(e_{1}+e_{2}-e_{1} e_{2}\right)
$$

Tripping rate of transmission line $i \quad P_{i}$ equals to the sum of tripping rate when fault occurs on itself and tripping rate when fault occurs on other lines but extends to line $i$.

Based on fault tripping rate, failure time and load loss under different neutral grounding conditions, the assessment of distributed network reliability are managed to be achieved, and the index of ASAI (average service 
availability index), CAIDI (customer average interruption duration index), and ENS (energy not supplied) can be calculated [20], illustrated as follow:

$$
\begin{gathered}
A S A I=\frac{\sum_{i}^{m} 8760 N_{i}-\sum_{i}^{m} U_{i} N_{i}}{\sum_{i}^{m} 8760 N_{i}} \\
\text { CAIDI }=\frac{\sum_{i}^{m} U_{S L i} N_{i}}{\sum_{i}^{m} f_{S L i} N_{i}} \\
\text { ENS }=\sum_{i}^{m} P_{a i} U_{S L i}
\end{gathered}
$$

Where, $m$ denotes the number of load point, $N_{i}$ is the number of customer connecting to load point $i, U_{S L i}$ is the outrage time of load point $i$ in one year, $f_{S L i}$ is the outrage rate of load point $i, P_{a i}$ is average load of load point $i$.

\section{Example}

Figure 2 is a RBTS Bus 2 system, which is composed by 2 main transformers, 4 transmission feeder lines, 36 lines and 22 load points with distribution transformers, and it is a medium voltage system of $33 / 11 \mathrm{kV}$ [21]. All the transmission line in the system are cables [22], and the parameters are: $\lambda=0.04, r=8, \eta=0.8, \delta=0.55, \alpha$ $=0.9, \beta=0.01, \zeta=0.2, e_{1}=e_{2}=0.1, m=2, \omega=0.5, \theta=0.5$. Assuming that the reliability indexes of this network are: $A_{\Gamma}=99.96 \%, C_{\Gamma}=3.5 h$. Service life of each device is $n=20$ years, annual rate $k=5 \%$, electricity production rate $c=5.27$ yuan $/ \mathrm{kWh}$, penalty coefficient $\alpha=1.5$.

The results of reliability indexes calculation under different neutral grounding mode are tabulated in Table 2. As we can see that under low resistance grounding mode, there is higher power supply availability, shorter customer interruption time and less power not supplied than that of other neutral grounding modes; the counterparts in neutral isolated system, resonance grounding system and high resistance grounding system not very much.

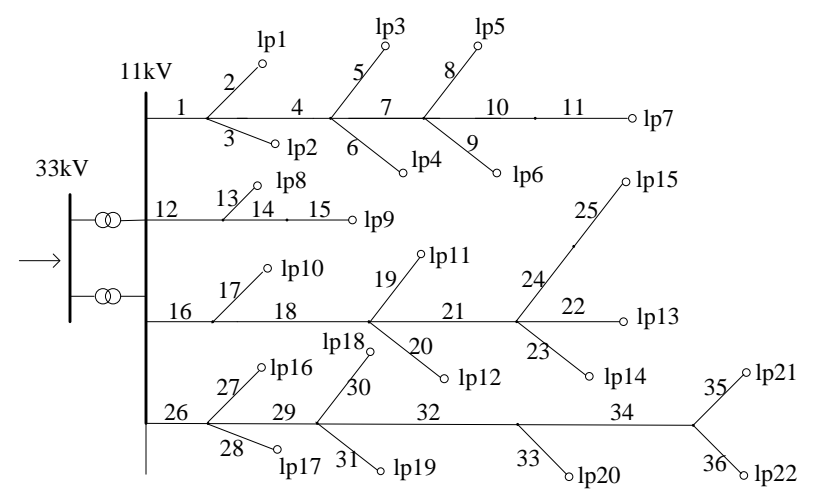

Figure 2. RBTS Bus 2 system diagram.

Table 2. Reliability index.

\begin{tabular}{cccc}
\hline Neutral grounding mode & ASAI & CAIDI & ENS (MW) \\
\hline Arc suppression coil grounding & $99.9633 \%$ & 3.2171 & 40.9126 \\
Low resistance grounding & $99.9707 \%$ & 2.5679 & 26.4863 \\
Ungrounded & $99.9614 \%$ & 3.3819 & 41.1909 \\
High resistance grounding & $99.9627 \%$ & 3.2662 & 38.3552 \\
\hline
\end{tabular}


Based on actual operation data and Electric power construction engineering budget quota, the items of investment costs by different neutral grounding methods can be obtained, as listed in Table 3, total costs are in Table 4.

Costs of repair in one year of different neutral grounding system are tabulated in Table 5 based on the statistic material. Equivalent annual obsolescence costs are also listed in Table 5 based on practical operation experience.

In accordance with the power not supplied in different neutral grounding system, interruption cost of one year can be obtained, as shown in Table 6.

Based on decision-making progression and objective functions in Figure 2 under different neutral grounding conditions, the results can be obtained, as Table 7 shows.

The objective function is bigger under both conditions of resonance grounding and high resistance grounding than under conditions of low resistance grounding and isolated neutral system. Under the limit of reliability level, power system with low resistance grounding method has the highest level of reliability, and also its objective function is the optimal function, in terms to a network as Figure 2, low resistance grounding method is recommended.

Table 3. Equipment investment costs.

\begin{tabular}{|c|c|c|c|c|c|c|}
\hline & $\begin{array}{c}\text { Scheme } \\
\text { (ten thousand yuan) }\end{array}$ & & $\begin{array}{c}\text { Neutral } \\
\text { grounding device }\end{array}$ & $\begin{array}{c}\text { Relay } \\
\text { protector }\end{array}$ & $\begin{array}{c}\text { Insulation } \\
\text { device }\end{array}$ & $\begin{array}{c}\text { Automatic } \\
\text { device }\end{array}$ \\
\hline \multirow{4}{*}{$\begin{array}{l}\text { Arc suppression } \\
\text { coil grounding }\end{array}$} & \multirow{3}{*}{$\begin{array}{c}\text { Initiative } \\
\text { investment }\end{array}$} & Acquisition & 27 & 22.5 & 23.6 & 49 \\
\hline & & Installation & 0.1 & 0.05 & 0.9 & 1.04 \\
\hline & & Other expense & 0 & 0 & 0.5 & 0 \\
\hline & \multicolumn{2}{|c|}{ Operation cost } & \multicolumn{4}{|c|}{5} \\
\hline \multirow{4}{*}{$\begin{array}{l}\text { Low resistance } \\
\text { grounding }\end{array}$} & \multirow{3}{*}{$\begin{array}{c}\text { Initiative } \\
\text { investment }\end{array}$} & Acquisition & 11 & 24.5 & 20.6 & 49 \\
\hline & & Installation & 0.1 & 0.05 & 0.6 & 1.04 \\
\hline & & Other expense & 0 & 0 & 0.2 & 0 \\
\hline & \multicolumn{2}{|c|}{ Operation cost } & \multicolumn{4}{|c|}{9} \\
\hline \multirow{4}{*}{ Ungrounded } & \multirow{3}{*}{$\begin{array}{c}\text { Initiative } \\
\text { investment }\end{array}$} & Acquisition & 0 & 10 & 26.6 & 35 \\
\hline & & Installation & 0 & 0.02 & 1.1 & 0.7 \\
\hline & & Other expense & 0 & 0 & 0.7 & 0 \\
\hline & \multicolumn{2}{|c|}{ Operation cost } & \multicolumn{4}{|c|}{2} \\
\hline \multirow{4}{*}{$\begin{array}{l}\text { High resistance } \\
\text { grounding }\end{array}$} & \multirow{3}{*}{$\begin{array}{c}\text { Initiative } \\
\text { investment }\end{array}$} & Acquisition & 16 & 23.5 & 24.6 & 41 \\
\hline & & Installation & 0.11 & 0.05 & 1 & 1.04 \\
\hline & & Other expense & 0 & 0 & 0.6 & 0 \\
\hline & \multicolumn{2}{|c|}{ Operation cost } & \multicolumn{4}{|c|}{4} \\
\hline
\end{tabular}

Table 4. Annual investment cost.

\begin{tabular}{cccc}
\hline Scheme (Unit: Ten thousand yuan) & $P$ & $a$ & Annual cost $G$ \\
\hline Ungrounded & 73.36 & 2 & 11.50 \\
Arc suppression coil grounding & 123.79 & 5 & 21.03 \\
High resistance grounding & 106.9 & 7 & 20.84 \\
Low resistance grounding & 106.49 & 9 & 22.79 \\
\hline
\end{tabular}


Table 5. Annual repair cost and obsolete cost.

\begin{tabular}{ccc}
\hline Scheme( Unit: Ten thousand yuan) & repair cost $X$ & Obsolete cost $F$ \\
\hline Ungrounded & 3.70 & -1.06 \\
Arc suppression coil grounding & 4.20 & -2.45 \\
High resistance grounding & 4.50 & -2.21 \\
Low resistance grounding & 4.90 & -1.94 \\
\hline
\end{tabular}

Table 6. Annual outage cost.

\begin{tabular}{ccc}
\hline Scheme & Power not supplied (MW) & Annual cost $K$ (Ten thousand yuan) \\
\hline Ungrounded & 41.1909 & 32.56 \\
Arc suppression coil grounding & 40.9126 & 32.34 \\
High resistance grounding & 38.3552 & 30.32 \\
Low resistance grounding & 26.4863 & 20.94 \\
\hline
\end{tabular}

Table 7. Annual total economic cost.

\begin{tabular}{cccccc}
\hline \multicolumn{1}{c}{ Cost } & $G$ & $X$ & $K$ & $F$ & $W$ \\
\hline Sheme & 11.50 & 3.70 & 32.56 & -1.06 & 46.70 \\
Arc suppression coil grounding & 21.03 & 4.20 & 32.34 & -2.45 & 55.12 \\
High resistance grounding & 20.84 & 4.50 & 30.32 & -2.21 & 53.45 \\
Low resistance grounding & 22.79 & 4.90 & 20.94 & -2.51 & 46.12 \\
\hline
\end{tabular}

\section{Conclusion}

As the development of power system, the neutral grounding mode diversified, to look for a method which can better fit the reliability, security and economy demands is significant for the planning and efficient operation of power system. Currently, decision about power system neutral grounding method lacks quantitative assessment, consequently synthetic decision is impeded, whereas, this paper proposed a decision method considering reliability indexes, and minimal life cycle cost based on reliability factors, via RBTS Bus 2 system the method is testified availably. This method synthesizes reliability security and economy demands, and can assure high economy and reliability, it provides effective computing method for neutral grounding design and planning of distribution network.

\section{References}

[1] Ping, S.-X. and Zhou, Y.-F. (2010) Power System Neutral Grounding Mode and Operation Analysis. China Electric Power Press, Beijing, 118-119.

[2] Su, J.-F. (2013) Research of Neutral Grounding Modes in Power Distribution Network. Power System Protection and Control, 41, 143-147.

[3] Guo, Q.-T. and Wu, T. (2010) Survey of the Methods to Select Fault Line in Neutral Point Ineffectively Grounded Power System. Power System Protection and Control, 38, 146-152.

[4] Fu, X.-Q., Xu, L.-Z. and Zhao, B.-L. (2010) Discussion on the Technology and Application of $10 \mathrm{kV}$ Distribution Network Neutral Grounding through Small Resistance. Power System Protection and Control, 38, 227-230.

[5] Dai, K.-M. (2000) Analysis on Neutral Grounding of Distribution System. Power System Technology, 24, 52-55.

[6] He, Z.-F. and Liu, P. (2002) Research of Neutral Point Grounding Modes in MV Distribution Network. Electric Power Automation Equipment, 22, 70-72. 
[7] Zhou, Y., Zhao, L.-J. and Kang, P. (2006) Neutral Grounding Mode of Urban Distribution Networks in Guizhou Province. Power System Technology, 30, 61-64.

[8] Zhao, R., Tan, W.-P. and Yang, Y.-H. (2007) Analysis of Neutral Grounding Operation Modes for Distribution Network. RELAY, 35, 22-26.

[9] Lin, Z.-C. (2004) The Selection and Application of Neutral Grounding Method of MV Network. High Voltage Engineering, 30, 60-64.

[10] Liu, M.-Y. (2004) Selection of Neutral Grounding Modes in Power Distribution Network. Power System Technology, 28, 86-89.

[11] Fu, Y.-S., Wang, Z.-G. and Kuang, S. (2006) Medium-Voltage Grid Grounding Comprehensive Selection Method. Power System Technology, 30, 101-106.

[12] Liu, Y., Nie, Y.-X. and Peng, X.-G. (2010) Application Research on the Mode Selection of Neutral Grounding with Fuzzy Reasoning Method. Power System Protection and Control, 38, 32-36.

[13] Cao, Z.-C., He, J.-S. and Yang, X.-C. (2007) Interval Analysis about Influence on Reliability of Power Distribution Lines with Various Grounded Neutrals. Guangxi Power, 5-7.

[14] Cao, Z.-C.,Wang, W.-L.,Yang, X.-C., et al. (2007) Decision Arithmetic of Neutral Grounding Mode Based on Interval Multiattribute Weighted Grey Target Theory. Guangxi Power, 1-5.

[15] Ramirez-Rosado, I.J. and Dominguez-Navarro, J.A. (2006) New Multi-Objective Tabu Search Algorithm for Fuzzy Optimal Planning of Power Distribution Systems. IEEE Transactions on Power Systems, 21, 224-233. http://dx.doi.org/10.1109/TPWRS.2005.860946

[16] Chen, D.-W. and Zhang, P.-M. (2011) Virtual Prototype Optimal Design of Intelligent AC Contactors Based on Artificial Fish-Swarm Algorithm. Transactions of China Electrotechnical Society, 26, 101-106.

[17] Su, H.-F., Zhang, J.-H., Liang, Z.-R., et al. (2012) Substation LCC Planning Based on Refined Mean Clustering Random Particle Swarm Algorithm. Transactions of China Electrotechnical Society, 27, 209-214.

[18] Luo, X.-C., Li, L. and Wei, Z.-L. (2011) Applications of Life Cycle Cost Theory in Decision-Making of Investment for Distribution Transformers Renovation. Power System Technology, 35, 207-210.

[19] Li, B. and Shu, H.-C. (2012) Applications of Life Cycle Cost Theory in Decision-Making of Investment for Distribution Transformers Renovation. Transactions of China Electrotechnical Society, 27, 183-190.

[20] Xu, J.-Z. and Li, Y. (2007) Reliability Assessment of Complex Distribution System Using GO Method. Transactions of China Electrotechnical Society, 22, 149-153.

[21] Billinton, R., Kumar, S., Goel, L., et al. (1989) A Reliability Test System for Educational Purposes-Basic Data. IEEE Transactions on Power Apparatus and System, 4, 1238-1244. http://dx.doi.org/10.1109/59.32623

[22] Ma, S.-C. (2008) Fault Location Techniques for Non-Effectively Earthed System Based on Transient Signals. Shandong University. 